\title{
Neonatal adjustments in respiratory and pulse rates in tropical breeds of buck-kids and doelings
}

\author{
Buhari Habibu ${ }^{1 *}$, Mohammed Umaru Kawu' ${ }^{1}$ Tagang Aluwong ${ }^{1}$ and Hussaina Joan Makun ${ }^{2}$
}

\begin{abstract}
Background: The transition to pulmonary respiration and the termination of foetal cardiovascular shunts is expected to commence immediately after birth. Subsequently, alveolar ventilation and tissue perfusion must be established, despite the challenge of extra-uterine environmental conditions, which could be quite demanding, even to the adult animals. The current study evaluated neonatal adjustment and diurnally induced changes in respiratory and pulse rates in kids of Red Sokoto, Sahel and West African Dwarf (WAD) goats in a tropical climate.

Results: Morning and afternoon respiratory rates started decreasing $(P<0.05)$ in the second week of birth. The pulse rate in the morning hours rose $(P<0.05)$ on Day 1 with no significant fluctuation subsequently, while the pattern in the afternoon hours showed a progressive decrease $(P<0.05)$ after birth. Apart from the day of birth, respiratory rate on other days increased significantly from morning to afternoon hours. The afternoon pulse rate was higher $(P<0.05)$ on the day of birth, but lower $(P<0.05)$ on Day 2 as compared to the morning values; and no diurnal difference was observed in subsequent days. The WAD goats had significantly higher respiratory and pulse rates than Red Sokoto and Sahel kids, especially in the afternoon hours. Similarly, the values were higher $(P<0.05)$ in doelings than buckkids during the morning hours. The correlation between respiratory and pulse rates was positive $(P<0.05)$ and the strength of the association increased with age.

Conclusion: It was concluded that the afternoon rise in ambient temperature induced the establishment of a clear diurnal variation in respiratory rate $24 \mathrm{~h}$ postnatal, while the diurnal variation in pulse rate was weak and irregular. The tropical climate may be quite challenging to the attainment of physiological stability in respiratory and cardiovascular functions of neonatal goat kids, especially during the hot season.
\end{abstract}

Keywords: Tropical goats, Neonatal changes, Diurnal variation, Postnatal life, Tropical climate

\section{Background}

Most of the physiological needs of the foetus in the uterine life is provided by the dam (Kasari 1994; Ravary-Plumioen 2009); however, in postnatal life, the neonate is left to cater for its needs. Some of such needs must be met immediately, while others may be temporarily provided, directly or indirectly by the dam. Respiration and heart

\footnotetext{
*Correspondence: buharihabibu@rocketmail.com

1 Department of Veterinary Physiology, Ahmadu Bello University, Zaria, Nigeria

Full list of author information is available at the end of the article
}

beat are immediate physiological needs that cannot wait and if they do wait, death may ensue. A series of cardiovascular and pulmonary physio-anatomical changes are necessary at birth for the survival of the neonate (Anton et al. 2019). Unlike other neonatal indicators of life, such as respiration and vocalization that start immediately after birth, heart beat or pulse pre-exist before parturition; and if breathing is not obvious after birth, heart beat or pulse is the main indicator of life (Hutchon 2016).

For the neonatal livestock to remain viable after birth, tissue oxygenation must be maintained through establishment of alveolar ventilation as well as central and 
peripheral circulation (Dwyer et al. 2015; Hutchon 2015). This is despite exposure to the novel environmental conditions, which is different from the highly controlled intra-uterine environment and is sometime difficult even to the adult animals (Piccione et al. 2007; Habibu et al. 2016). One of such important ambient complication is diurnal variation in environmental temperature and relative humidity from morning to afternoon hours which may induce thermal stress, especially in the tropics (Minka and Ayo 2016; Giannetto et al. 2017). Thus, while neonatal livestock have to maintain tissue oxygenation, diurnal rhythm in respiratory and pulse rates must be established to support homeostasis and complete physiological maturation (Habibu et al. 2016; Giannetto et al. 2017). In tropical regions like Nigeria, ambient temperature seems to have the greatest influence on diurnal biological rhythm, as the tropical photoperiod has minimal or no physiological effect, due to the small amplitude or relatively stable photoperiod (approximately one hour) from one season to the other (Habibu 2015).

The suprachiasmatic nuclei ( $\mathrm{SCN}$ ) is responsible for circadian oscillation of respiratory and heart rates (Refinetti 2006). Previous studies showed that circadian rhythm in respiratory and heart rates is poorly developed in neonatal animals (Weinert et al. 1994; Piccione et al. 2005). In goat kids specifically, Giannetto et al. (2017) reported no rhythmicity as a group, but showed rhythmicity in heart and respiratory rates in some kids in the early hours of birth. Generally data on neonatal physiology of goats are rare and the available studies on the diurnal variations in heart and respiratory rates were conducted in the temperate climates. This is despite the fact that the tropical climate has greater impact on diurnal rise in ambient temperature due to heat stress, with an established early morning (06:00-07:00 h) diurnal nadir and afternoon (13:00-14:00 h) zenith (Minka and Ayo 2016; Yaqub et al. 2021). This is expected to pose additional physiological stress to the neonatal goats already faced with the challenge of adjusting to a new life. It is believed that data from the current study may provide valuable information on neonatal adaptation and welfare of tropical goat kids in the early days of birth and may be helpful in the management, diagnosis and prevention of neonatal health conditions. Hence, the aim of the study was to evaluate neonatal changes and diurnal rhythm in respiratory and pulse rates in tropical breeds of buck-kids and doelings in a tropical hot climate.

\section{Methods}

\section{Experimental location and animal management}

The study was carried out in the National Animal Production Research Institute (NAPRI), Ahmadu Bello University, Shika, Nigeria (latitudes 11 and $12^{\circ} \mathrm{N}$ and longitudes
7 and $\left.8^{\circ} \mathrm{E}\right)$. The study protocol and experimental design got the approval of the Animal Use and Welfare Committee of Ahmadu Bello University and obtained an approval number: ABUCAUC/2019/13. The animals were managed semi-intensively, housed in concretefloored and half-walled pens. The pens were well ventilated and roofed with galvanized metal sheet with each having dimensions of 6.1, 6.1 and $2.2 \mathrm{~m}$ for length, width and height, respectively. Each pen had a stocking density of 20 does. The animals were allowed to graze in natural pasture during the day and supplemented with Digitaria smutsi hay and concentrate ration (ground maize: $20 \%$; cotton seed cake; $30 \%$; wheat offal: $40 \%$; bone meal: $5 \%$ and table salt: $5 \%$ ) at $3 \%$ body weight per day. Water was provided ad libitum. After parturition, the kids were allowed to suckle their mothers directly. Health status of the goats was evaluated based on behavior, appetite and faecal consistency. Animals on the farm were routinely screened for haemoparasites and helminths, and only clinically healthy animals were used for the study.

\section{Animal breeding and study design}

Apparently healthy cycling adult does with parity of 1-2 were synchronized using cloprostenol (Synchromate ${ }^{\circledR}$ ) in the month of November. To achieve that, $0.263 \mathrm{mg} / \mathrm{mL}$ was administered at the dose of $1 \mathrm{~mL}$ per doe $(1 / 2$ of the manufacturer's recommended dose for a cow) using a single intra-muscular injection into the thigh muscle. After $24 \mathrm{~h}$ of treatment, the does were observed for signs of oestrus. Does that showed signs of oestrus were housed in separate pens of 5 does per pen and a proven buck was introduced to each pen. The five does and one buck in each pen were allowed to stay together for 4 weeks.

After parturition, the sex of the kids and fecundity of the dam were recorded. Only single-born kids were used for the study. A total of 39 single-born kids belonging to Red Sokoto $(n=13)$, Sahel $(n=13)$ and West African Dwarf $(n=13)$ goats were randomly selected from the dams that kidded and were used for the study. Of the kids used 18 were buck-kids (5 Red Sokoto, 8 Sahel and 5 WAD kids) and 21 were doelings ( 8 Red Sokoto, 5 Sahel and 8 WAD kids). The kids were allowed to suckle for $10 \mathrm{~min}$ after the commencement of first suckling to further strengthen maternal-kid bonding. The kids were then restrained gently by an experienced personnel, using a gloved-hand to record the pulse rate in the morning $(07: 00 \mathrm{~h})$ and afternoon (13:00 $\mathrm{h}$ ) hours on Days 0, 1 , 2, 8, 10 and 20, postnatal. These time points during the day represent the established diurnal nadir and zenith, respectively (Minka and Ayo 2016; Yaqub et al. 2021).

Respiratory rate was obtained by counting the movements of the flank at the paralumbar fossa per unit time and was presented as number of cycles per minute 
(Saddiqi et al. 2011). Pulse rate was obtained by counting the pulsations felt on the femoral artery per unit time and was presented as number of beats per minute (Habibu et al. 2017; Yaqub et al. 2021).

The dry-bulb (ambient) and wet-bulb temperatures at the experimental site were measured, using dry- and wetbulb thermometer (GH Zeal limited, London, England), in the morning $(8: 00 \mathrm{~h})$ and afternoon $(13: 00 \mathrm{~h})$ hours on the days the physiological parameters were recorded. The relative humidity was calculated using conversion tables condensed from the Bulletin of the US Weather Bureau No. 1071. The values of temperature humidity index (THI) were deduced from dry bulb temperatures and relative humidity using the formula by Ravagnolo et al. (2000): on respiratory rate of neonatal goats is presented in Figs. 1 and 2 for the morning and afternoon hours, respectively, and in Table 2 for the overall data, irrespective of age. Unlike the morning respiratory rate in WAD goats that showed no significant change with age, the pattern in Red Sokoto and Sahel goats showed significant decrease $(P<0.05)$ with age. In WAD kids, the high morning respiratory rate at birth was maintained with no significant fluctuation throughout the course of the study (birth to Days 20). Hence, a significant decrease was observed on Day 10 in Red Sokoto kids and on Day 20 in Sahel kids after birth. On Days 2, 8 and 20, Sahel kids had significantly lower morning respiratory rate than WAD kids, while on Day 20 the value

$$
\begin{aligned}
\mathrm{THI}= & (1.8 \times T+32)-\{(0.55-0.0055 \cdot \mathrm{RH}) \cdot(1.8 \times T-26)\} \\
& \cdot \text { Where: } T=\text { ambient temperature }\left({ }^{\circ} \mathrm{C}\right) \\
& \text { and } \mathrm{RH}=\text { relative humidity }(\%) .
\end{aligned}
$$

\section{Data analysis}

The effects of breed, sex, diurnal variation and age of kids were determined using repeated measure two-way analysis of variance (ANOVA), while means were separated using Bonferroni test to compare values. The meteorological data were subjected to paired sample t-test for comparison between morning and afternoon hours. Pearson's correlation was used to determine the relationships between respiratory and pulse rates. Comparisons in all cases were done at the $5 \%$ level of significance. The statistical package used was GraphPad Prism version 9.0.0 for windows (2020) from GraphPad software LLC, San Diego California, USA.

\section{Results}

The impact of the ambient conditions in the experimental pens is presented in Table 1 . The ambient temperature and THI significantly increased $(P<0.05)$ in the afternoon hours, whereas the relative humidity decreased in the afternoon hours. The effect of breed

Table 1 Mean ( \pm SEM) values of meteorological parameters in the study area

\begin{tabular}{lll}
\hline Parameters & Morning & Afternoon \\
\hline Ambient temperature $\left({ }^{\circ} \mathrm{C}\right)$ & $25.34 \pm 0.61 \mathrm{a}$ & $34.04 \pm 0.90 \mathrm{~b}$ \\
& $(23.00-31.50)$ & $(30.60-39.00)$ \\
Relative humidity (\%) & $72.33 \pm 5.69 \mathrm{a}$ & $54.67 \pm 5.43 \mathrm{~b}$ \\
& $(22.00-92.00)$ & $(33.00-96.00)$ \\
Temperature-humidity index & $70.37 \pm 1.156 \mathrm{a}$ & $77.05 \pm 0.95 \mathrm{~b}$ \\
& $(63.15-75.02)$ & $(72.13-81.93)$ \\
\hline
\end{tabular}

Values with $\mathrm{a}, \mathrm{b}$ are significantly different $P<0.05$

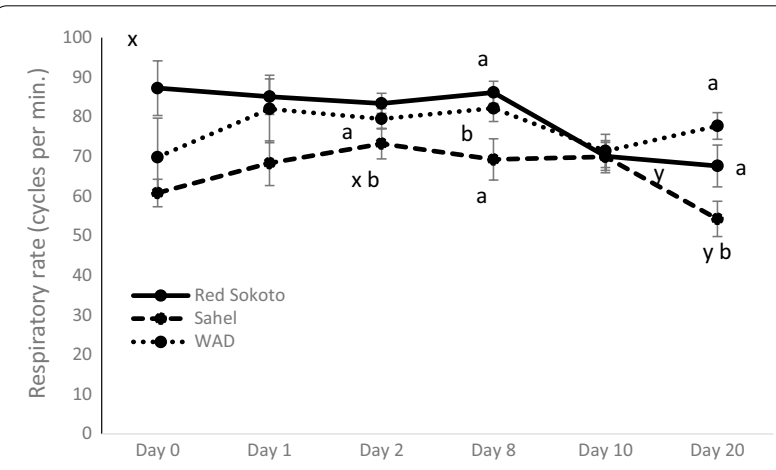

Fig. 1 Changes in morning respiratory rate in different breeds of neonatal Nigerian goats from birth to Day 20. Values with $a, b$ and $x, y$ indicate significantly different $(P<0.05)$ between different breeds and ages, respectively

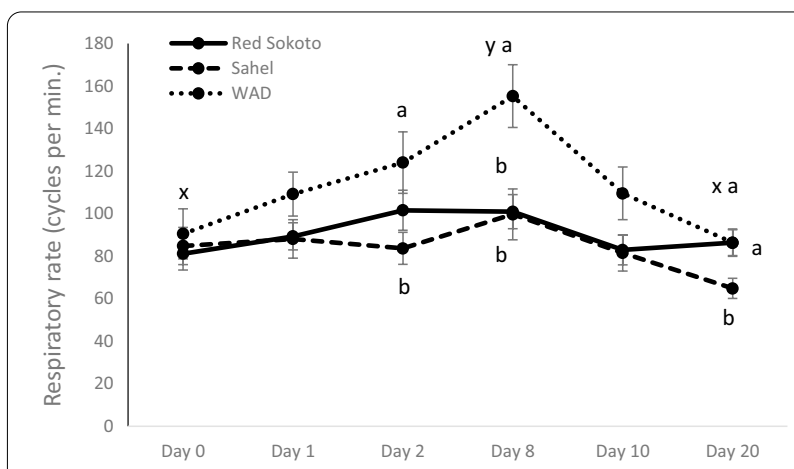

Fig. 2 Changes in afternoon respiratory rate in different breeds of neonatal Nigerian goats from birth to Day 20 . Values with $a, b$ and $x, y$ indicate significantly different $(P<0.05)$ between different breeds and ages, respectively 
Table 2 Effects breed and sex on diurnal variation in respiratory rate (cycles per min.) of neonatal tropical goats

\begin{tabular}{lcc}
\hline & Morning & Afternoon \\
\hline Red Sokoto & & \\
Female & $79.94 \pm 3.14$ & $90.92 \pm 6.51$ \\
Male & $79.87 \pm 3.97$ & $78.11 \pm 5.31$ \\
Overall & $79.91 \pm 2.56 \mathrm{a}$ & $82.92 \pm 11.22$ \\
Sahel & & \\
Female & $66.67 \pm 4.25$ & $83.56 \pm 12.18$ \\
Male & $65.50 \pm 3.36$ & $102.06 \pm 12.19$ \\
Overall & $65.95 \pm 2.56 \mathrm{~b}$ & $99.375 \pm 11.22$ \\
WAD & & \\
Female & $78.80 \pm 4.74$ & $108.89 \pm 15.17$ \\
Male & $72.27 \pm 4.74$ & $113.08 \pm 13.14$ \\
Overall & $76.75 \pm 2.66 \mathrm{a}$ & $115.88 \pm 7.93$ \\
\hline
\end{tabular}

Values with $\mathrm{a}, \mathrm{b}$ for the overall data are significantly different $P<0.05$

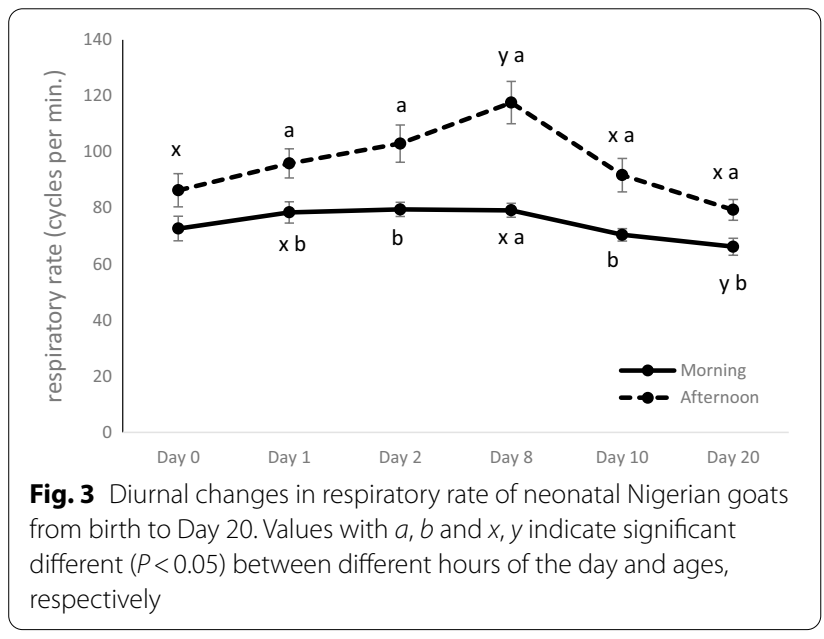

was lower than that of Red Sokoto kids. Similarly, the Red Sokoto kids had higher morning respiratory rate than WAD kids on Day 8.

The afternoon pattern of respiratory rate in the neonatal goats differed from the changes observed in the morning hours, given that no significant fluctuation was recorded in Red Sokoto and Sahel goats from birth to Day 20 in the afternoon hour, while WAD kids had a rise on Day 8 and subsequent decrease on Day 20. Similarly, WAD kids had higher $(P<0.05)$ afternoon respiratory rate than Red Sokoto and Sahel kids on Days 8 and Days 2, 8 and 20, respectively. It was also observed that, Red Sokoto kids had higher values on Day 20 as compared to Sahel kids. In the overall data, Sahel kids had lower $(P<0.05)$ respiratory rate than Red Sokoto and WAD kids in the morning hours, but no significant difference $(P>0.05)$ was observed during the afternoon hours.

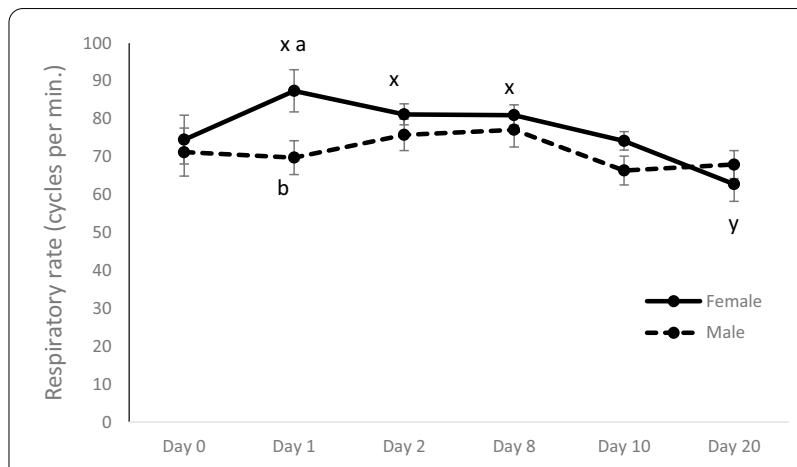

Fig. 4 Changes in morning respiratory rate of neonatal buck-kids and doelings from birth to Day 20. Values with $a, b$ and $x, y$ indicate significant different $(P<0.05)$ between different sexes and ages, respectively

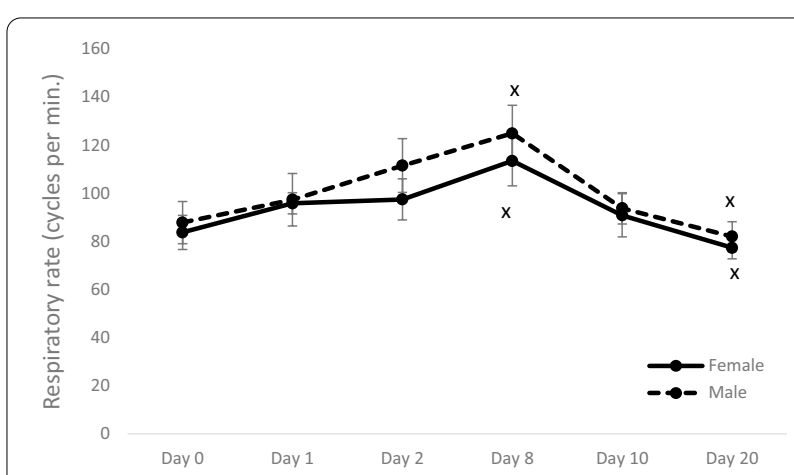

Fig. 5 Changes in afternoon respiratory rate of neonatal buck-kids and doelings from birth to Day 20. Values with $a, b$ and $x, y$ indicate significant different $(P<0.05)$ between different ages

Diurnal changes in respiratory rate between the morning and afternoon hours in neonatal breeds of goats are presented in Fig. 3. The respiratory rate increased from morning to afternoon hours from the day of birth to Day 20 and the rise in all the days were significant $(P<0.05)$, except on the day of birth. Similarly, the pattern of respiratory rate in the morning hours in Fig. 3 showed no significant fluctuations after birth but a decrease $(P<0.05)$ was observed on Day 20; the pattern in the afternoon hours showed a significant rise on Day 8 , followed by a subsequent decrease on Day 10.

On all the days, apart from Day 20, the morning respiratory rate was higher in doeling than buck-kids; but the values were only significantly $(P<0.05)$ on Day 1 (Fig. 4$)$. The morning respiratory rate in doelings decreased significant from birth to Day 20, while the buck-kids showed no significant fluctuation from birth to Day 20. In the afternoon hours (Fig. 5), the respiratory rate significantly rose on Day 8 and subsequently decreased $(P<0.05)$ on Day 20. No significant $(P>0.05)$ sex difference in respiratory rate was observed in the afternoon hours. 


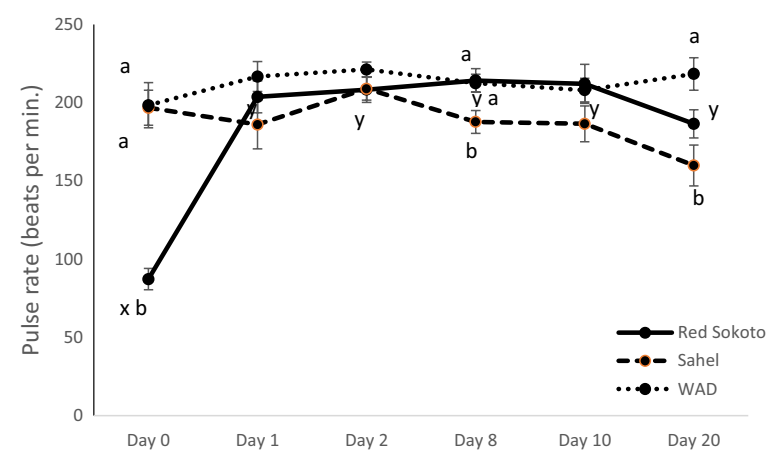

Fig. 6 Changes in morning pulse rate in different breeds of neonatal Nigerian goats from birth to Day 20. Values with $a, b$ and $x, y$ indicate significantly different $(P<0.05)$ between different breeds and ages, respectively

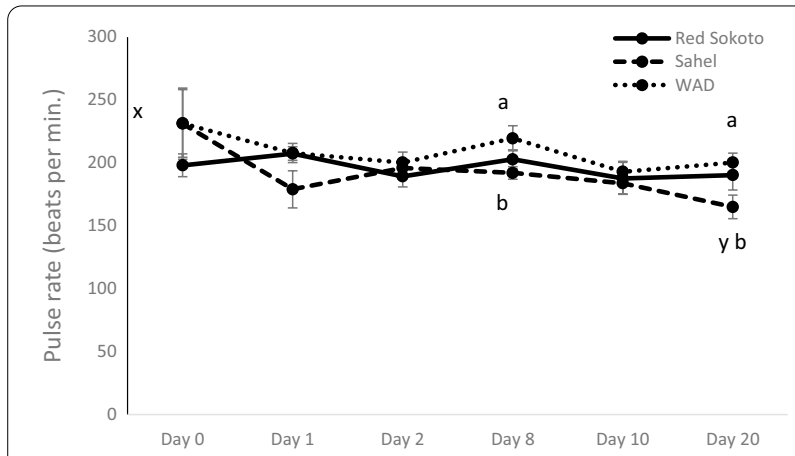

Fig. 7 Changes in afternoon pulse rate in different breeds of neonatal Nigerian goats from birth to Day 20 . Values with $a, b$ and $x, y$ indicate significantly different $(P<0.05)$ between different breeds and ages, respectively

Table 3 Effects breed and sex on diurnal variation in pulse rate (beats per min.) of neonatal tropical goats

\begin{tabular}{lll}
\hline & Morning & Afternoon \\
\hline $\begin{array}{l}\text { Red Sokoto } \\
\text { Female }\end{array}$ & $184.33 \pm 7.41$ & $202.17 \pm 17.65$ \\
Male & $186.87 \pm 9.37$ & $179.33 \pm 8.83$ \\
Overall & $185.31 \pm 5.89 \mathrm{a}$ & $179.33 \pm 8.11 \mathrm{a}$ \\
Sahel & & \\
Female & $206.37 \pm 8.34 \mathrm{x}$ & $178.96 \pm 17.13$ \\
Male & $175.85 \pm 6.59 \mathrm{y}$ & $183.44 \pm 17.13$ \\
Overall & $187.59 \pm 5.89 \mathrm{a}$ & $187.37 \pm 7.26 \mathrm{a}$ \\
WAD & & \\
Female & $214.07 \pm 9.05$ & $208.70 \pm 4.79$ \\
Male & $203.17 \pm 10.12$ & $207.83 \pm 5.36$ \\
Overall & $210.77 \pm 6.72 \mathrm{~b}$ & $209.15 \pm 5.13 \mathrm{~b}$ \\
\hline
\end{tabular}

Values with $a, b$ for the overall data between breeds and $x, y$ for different sexes are significantly different $P<0.05$

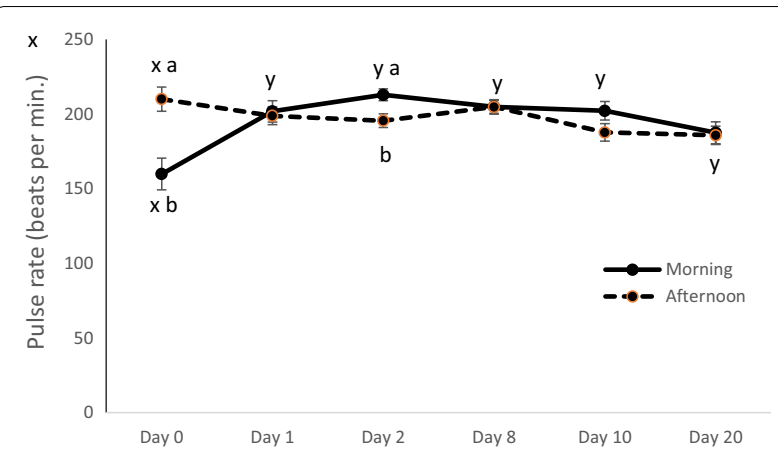

Fig. 8 Diurnal changes in pulse rate of neonatal Nigerian goats from birth to Day 20. Values with $a, b$ and $x, y$ indicate significant different $(P<0.05)$ between different hours of the day and ages, respectively

The effect of breed on pulse rate of neonatal Nigerian goats is presented in Figs. 6 and 7 for morning and afternoon hours, respectively, and in Table 3 for the overall data, irrespective of age. The pattern in the morning hours showed significant fluctuation $(P<0.05)$ only in Red Sokoto kids; the patterns in other breeds showed no significant $(P>0.05)$ change. A significantly lower $(P<0.05)$ morning pulse rate was observed in Red Sokoto when compared with Sahel and WAD kids on the day of birth; this was followed by a marked increase $(P<0.05)$ on Day 1 in Red Sokoto kids, from when the value remained stable, with no significant fluctuation until the end of the study. The Sahel kids had lower $(P<0.05)$ morning pulse rate than Red Sokoto and WAD kids on Day 8 and also lower value than WAD kids alone on Day 20. Likewise, in the afternoon hours, Sahel kids had lower pulse rate than WAD kids on Days 8 and 20. Only Sahel kids showed a significant decrease in afternoon pulse rate from birth to Day 20 (Fig. 7). In the overall data, irrespective of age, WAD kids had higher pulse rate than Red Sokoto and Sahel goats.

In contrast to the pattern observed in respiratory rate, weak and irregular diurnal changes were observed in pulse rate between the morning and afternoon hours in the neonatal goats (Fig. 8); such that the value in the morning hours was significantly lower $(P<0.05)$ than that of the afternoon hours on the day of birth. Subsequently, on Day 2, the pulse rate significantly increased in the morning and decreased $(P<0.05)$ in the afternoon hours. No diurnal changes were observed in subsequent days of the study. In Fig. 8, morning pulse rate rose on Day 1 and remained relatively stable subsequently, while the afternoon pulse rate decreased from birth to Day 20.

Neonatal doelings had significantly $(P<0.05)$ higher pulse rate in the morning hours of Day 1 (Fig. 9) and in 


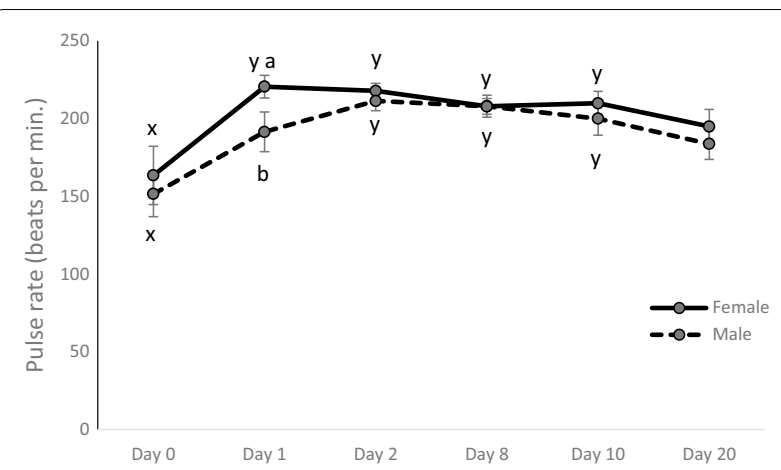

Fig. 9 Changes in morning pulse rate of neonatal buck-kids and doelings from birth to Day 20. Values with $a, b$ and $x, y$ indicate significant different $(P<0.05)$ between different sexes and ages, respectively

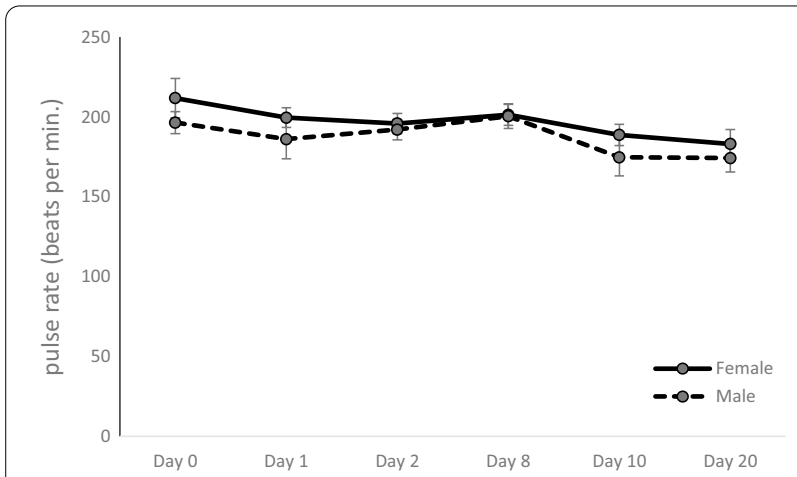

Fig. 10 Changes in afternoon pulse rate of neonatal buck-kids and doelings from birth to Day 20

the overall data for Sahel kids (Table 3). In the afternoon hours (Fig. 10 and Table 3), however, no significant effect of sex was observed. Also, while both buck-kids and doelings showed an increased $(P<0.05)$ in pulse rate from birth to Day 1 and remained relatively stable afterward, no significant fluctuations were observed during the afternoon hours. Pearson's correlation (Table 4) showed significantly positive correlation between respiratory and pulse rates on Days 1, 8 and 20 with the association being progressively stronger with age $(r=0.27,0.30$ and 0.49 , respectively).

\section{Discussion}

The irregular pattern in neonatal respiration noted immediately after birth is characterized by different periods of apnea, eupnea and tachypnea (Piccione et al. 2007; Hilaire and Duron 1999). The first breath marks the onset of external ventilation, clearance of the foetal pulmonary fluid and establishment of functional residual capacity (Piccione et al. 2007; Saddiqi et al. 2011). Agreeing with the current study, a number of studies reported a decrease in respiratory rate, postnatal. Although, different reports exist as to when the decrease in respiratory rate is recorded, most studies indicated a decrease before the fifth week after birth (Mortola 1984; Piccione et al. 2007; Samimi 2019; Arfuso et al. 2021). A marked decrease in respiratory rate compared with the day of birth was observed on the second day in kids (Fazio et al. 2016), Day 24 in kids and lambs (Samimi 2019) and fifth week in lambs (Piccione et al. 2007). In the current study, the respiratory rate remained relatively stable after birth until Day 10 or 20, when the decrease was observed in most groups in both morning and afternoon hours; though in the afternoon hours, a rise on Day 8 was observed before the subsequent decrease. In agreement with changes observed in the current study during the afternoon hours, Piccione et al. (2007) also reported an initial increase in the second week before a subsequent decrease in the fifth week after birth. The high respiratory rate in the early neonatal life as compared with the late neonatal life is a necessity to meet neonatal energy demand (Mortola 1984; Piccione et al. 2007). Neonatal mammals have higher metabolic rate per unit body weight compared to adults. Thus, they require a relatively

Table 4 Pearson's correlation between respiratory and pulse rate in neonatal Nigerian goats from birth to Day 20

\begin{tabular}{|c|c|c|c|c|c|c|}
\hline & \multicolumn{6}{|c|}{ Respiratory rate } \\
\hline & Day 0 & Day 1 & Day 2 & Day 8 & Day 10 & Day 20 \\
\hline \multicolumn{7}{|c|}{ Pulserate } \\
\hline Day 0 & 0.15 & 0.09 & 0.01 & 0.16 & 0.25 & -0.00 \\
\hline Day 1 & -0.09 & $0.27^{*}$ & -0.02 & -0.02 & -0.03 & -0.19 \\
\hline Day 2 & -0.11 & 0.09 & 0.18 & -0.02 & -0.15 & -0.11 \\
\hline Day 8 & 0.24 & $0.35^{* *}$ & $0.26^{*}$ & $0.30^{* *}$ & 0.22 & 0.15 \\
\hline Day 10 & 0.02 & 0.16 & 0.12 & 0.07 & 0.01 & 0.18 \\
\hline Day 20 & 0.07 & 0.19 & 0.14 & 0.04 & 0.08 & $0.49^{* *}$ \\
\hline
\end{tabular}

Values with asterisk are significantly ${ }^{*} P<0.05 ;{ }^{* *} P<0.001$ 
higher minute ventilation which in goats seems to be best supplied by increase in respiratory rate. The relatively small size and high surface area-to-body mass ratio of the neonate require higher metabolic rate per unit body weight than in the adult to account for temperature dispersion (Mortola 1984).

The environmental variables recorded in the current study were slightly higher than the thermoneutral zone for ambient temperature $\left(24-30{ }^{\circ} \mathrm{C}\right)$ and THI $(65-75)$ in goats (Lu 1989; Hamzaoui et al. 2013), and coupled with the challenge of early neonatal novelty (Piccione et al. 2007; Samimi 2019), the neonatal goats were exposed to significant level of heat stress during the afternoon hours. The WAD kids had higher respiratory rate as compared to Red Sokoto and Sahel kids, especially in the afternoon hours. Higher metabolic rate is anticipated in WAD goats due to their miniature conformation as compared with Red Sokoto and Sahel goats (Ngere et al. 1984; Bennett and Tenney 1982). Thus, with rise in ambient temperature during the afternoon hours, sensible heat loss becomes compromised and the WAD kids have to engage in active evaporative heat loss by increasing their respiratory rate to prevent development of hyperthermia (Yaqub et al. 2021).

It is well established that the afternoon rise in ambient temperature and THI stimulates a thermoregulatory increase in respiratory and pulse rates in adult tropical goats to enhance heat dissipation (Hamzaoui et al. 2013; Yaqub et al. 2021). In the current study, respiratory rate on the day of birth did not significantly increase in the afternoon hours; but subsequently, from Day 1, the respiratory rate showed clear diurnal rhythmicity throughout the course of the study. In a similar study, Giannetto et al. (2017) reported rhythmicity in respiratory rate in only one out of 13 kids in the first $33 \mathrm{~h}$ of birth. The non-significant afternoon rise in respiratory rate on the day of birth in the current study suggest greater investment in external ventilation to meet body oxygen demand rather than engage in thermoregulation. On the following day when respiratory system compliance has increased and resistance has reduced (Piccione et al. 2007; Mortola 1984), pulmonary thermoregulatory function then commenced. The concomitant effects of high neonatal respiratory rate and thermoregulatory-induced hyperventilation resulted in a markedly higher value of respiratory rate in the tropical goat kids. Thermoregulatory-induced hyperventilation may predispose the neonatal kids to dehydration and hypocapnia, distorting the plasma ratio of bicarbonate to carbon dioxide tension (20:1) and interfere with acid-base balance (Masero and Siegel 1977; Habibu et al. 2019). In a previous study, acute heat stress in goat kids caused both respiratory alkalosis and metabolic acidosis, with metabolic acidosis predominating, particularly when the duration of the acute heat exposure is prolonged (Temizel et al. 2009; Habibu et al. 2019).

One physiological activity that must continue after birth is the beating of the heart to pump blood to the lungs and other tissues for the commencement of "self" blood oxygenation (Ravary-Plumioen 2009). Previous studies in neonatal ruminants agrees with the findings of the current study, which showed reduction in pulse rate after birth, from when (Day 20 postnatal) the value is expected to change to a lower adult value (Saddiqi et al. 2011; Plush et al. 2016; Samimi 2019; Arfuso et al. 2021). Most researches reported a decrease in heart or pulse rate of neonatal small ruminant before the first month of birth (Piccione et al. 2007; Saddiqi et al. 2011; Fazio et al. 2016; Samimi 2019).

However, unlike in previous studies (Piccione et al. 2007; Fazio et al. 2016), the current study recorded an initial rise from a lower value of pulse rate at birth to a higher value on Day 1 in the morning hours, which remain relatively stable until the decrease on Day 20. In Red Sokoto goats, especially, a twofold increase in pulse rate was observed from birth to Day 1 in the morning hours, but not in the afternoon hours. Conversely, existing studies reported the establishment of higher heart or pulse rate during the early neonatal period than at any other time in the life of animals (Piccione et al. 2007; Saddiqi et al. 2011). This initial rise is possibly in response to rise in systolic volume caused by colostrum intake, since the heart is not yet able to vary cardiac output (Buschmann et al. 1993). The higher afternoon pulse rate observed on the day of birth is presumably due to the thermoregulatory challenge induced by heat stress (Hamzaoui et al. 2013; Yaqub et al. 2021). This change resulted in diurnal variation in pulse rate on the day of birth, which was followed by another diurnal variation on Day 2 that was obverse to the pattern observed on the day of birth. On subsequent days, no significant diurnal rhythmicity in pulse rate was observed. This chaotic behavioral tendency may also infer immaturity in the functioning of the SCN and/or autonomic nervous system (Finley et al. 1987; Refinetti 2006), especially in the presence of a complicating ambient factor, which is probably heat stress. This pattern may compromise cutaneous thermoregulation by reducing perfusion of the skin which may impair sensible and insensible heat loss in the afternoon hours, while undermining body heat conservation in the morning hours (Habibu et al. 2019; Yaqub et al. 2021). In neonatal goats, rhythmicity of heart rate is poorly developed (Giannetto et al. 2017) and data in humans showed that the development may only be 
completed in one to a few months after birth (Ardura et al. 2004; Glotzbach et al. 1994; Massin et al. 2000).

The small body size of the WAD goats (Gall 1996) may account for the higher pulse rate in the said breed as body size is proportional to heart rate in genetically different groups of animals with marked difference in body size (Detweiler 2010). The markedly lower pulse rate in Red Sokoto kids ( $87.23 \pm 6.89$ beats/min) at birth contradicts the well-established higher heart beat at birth as observed in the current study in Sahel $(196.69 \pm 9.21$ beats/min) and WAD (198.33 \pm 10.40 beats/min) kids, as well as in previous studies reported by Fazio et al. (2016) in Maltese kids (194 \pm 4 beats/min) and Samimi (2019) in Cashmere kids (184 \pm 3 beats/min). This 'neonatal bradycardia' in Red Sokoto breed at birth may imply greater immediate postnatal cardiovascular challenge, which has to be overcome to increase cardiac activity to the higher neonatal status, explaining the more than twofold increase in pulse rate ( $203.63 \pm 9.18$ beats $/ \mathrm{min}), 24 \mathrm{~h}$ later.

The higher respiratory and pulse rates during the morning hours in doelings than buck-kids indicates gender dimorphism in these parameters even at the neonatal stage and infers the influence of gender in physiological adjustments of respiratory and pulse rates in tropical goat kids. However, in the afternoon hours when the kids were challenged with the effects of higher ambient temperature, the gender dimorphism was not noticed, since both kids had to maximize heat dissipation by increasing respiratory rate (Hamzaoui et al. 2013; Yaqub et al. 2021).

An age-dependent increase in the positive correlation between respiratory and pulse rates was observed on Days 1, 8 and 20, suggesting that a poor association exists between the two physiological variables at birth as each contends independently with the challenges of immediate postnatal life. After $24 \mathrm{~h}$, an association between the two begins to develop and with age it became stronger due to maturation of the autonomic nervous system and the SCN (Refinetti 2006; von Walter et al. 2010; Crandall and Wilson 2015).

\section{Conclusions}

In conclusion, neonatal adjustments in respiratory and pulse rates after birth in tropical goats were influenced by breed and sex, and the challenge of adaptive response of the neonates was made more complicated by the afternoon rise in ambient heat load, likely due to heat stress. A clear diurnal variation in respiratory rate that was established, $24 \mathrm{~h}$ postnatal, while the diurnal variation in pulse rate was irregular and weak. At some points during early neonatal adjustment, diurnal changes in respiratory and pulse rates may compromise cutaneous thermoregulation and predispose neonatal tropical goats to acid-base challenges. A twofold increase, $24 \mathrm{~h}$ postnatal was observed in neonatal Red Sokoto goats, which is suggestive of greater postnatal cardiovascular challenge. Inherent factors of gender (as in the doelings) and body size (as with hereditary dwarfism in WAD), especially in the morning hours, were associated with higher respiratory and pulse rates. An age-dependent increase exists in the association between respiratory and pulse rates, which only started, $24 \mathrm{~h}$ postnatal. Findings of the current study suggest the need for adequate provision of milk and drinking water for rehydration and the use of well ventilated pen for kidding in tropical goats.

\section{Abbreviations}

WAD: West African Dwarf; NAPRI: National Animal Production Research Institution; THI: Temperature humidity index; RH: Relative humidity; SCN: Suprachiasmatic nuclei; Min: Minute; h: Hour.

\section{Acknowledgements}

The Management of National Animal Production Research Institute, Ahmadu Bello University, Shika, Zaria, granted the permission to use the institute physical facilities for the study. The goats were provided by the TETFUND Project: TETFUND/DESS/NRF/ABUZARIA/STI/NOL1/B45. Staff of Department of Veterinary Physiology as well as those of Diary Research Programme, NAPRI, Ahmadu Bello University, Kaduna State gave technical assistance. Prof. C.A. Kudi of Department of Veterinary Medicine, Ahmadu Bello University, Zaria vetted the manuscript.

\section{Authors' contributions}

$\mathrm{BH}$ and MUK developed the experimental design. BH, TA and MUK prepared the manuscript. In particular, $\mathrm{BH}$ and HJM carried out the field work. $\mathrm{BH}$ analyzed and interpreted the data. All authors read and approved the final manuscript.

\section{Funding}

No funding was received for this study; all logistics were supported privately by the authors.

\section{Availability of data and materials}

All analyzed data are included in the article.

\section{Declarations}

\section{Ethics approval and consent to participate}

The study protocol and experimental design got the approval of the Animal Use and Welfare Committee of Ahmadu Bello University and obtained an approval number: ABUCAUC/2019/13. Consent to participate is not applicable to current study given that the animals were under the supervision and management of members of the research team (the authors).

\section{Consent for publication}

Not applicable.

\section{Competing interests}

The authors declare that they have no competing interests.

\section{Author details}

${ }^{1}$ Department of Veterinary Physiology, Ahmadu Bello University, Zaria, Nigeria. ${ }^{2}$ National Animal Production Research Institute, Ahmadu Bello University,

Zaria, Nigeria.

Received: 12 August 2021 Accepted: 26 October 2021

Published online: 04 November 2021 


\section{References}

Anton O, Fernandez R, Rendon-Morales E, Aviles-Espinosa R, Jordan H, Rabe $H$ (2019) Heart rate monitoring in newborn babies: a systematic review. Neonatology 116:199-210

Ardura J, Andres J, Aragon MP, Agapito T (2004) Congenital anophthalmia: a circadian rhythm study. Chronobiol Int 21:315-321

Arfuso F, Giannetto C, Giudice E, Assenza A, Piccione G (2021) Daily dynamic changes of blood acid-base status and vital parameters in lambs and goat kids over the first seven days after birth. Small Rum Res. https://doi. org/10.1016/j.smallrumres.2021.106340

Bennett FM, Tenney SM (1982) Comparative mechanics of the mammalian respiratory system. Respir Physiol 49:131-140

Buschmann H, Hoffmann B, Kamphues J, Meyer H, Walzer K (1993) Anatomy and physiology of the newborn. In: Walzer K, Bostedt H (eds) Neonatal diseases of the animals. Agricole, pp 1-44

Crandall CG, Wilson TE (2015) Human cardiovascular responses to passive heat stress. Compr Physiol 5(1):17-43

Detweiler DK (2010) The mammalian electrocardiogram: comprehensive features: interspecies correlations: body size, heart rate and time intervals. In: Macfarlane PW, van Oosterom A, PahIm O, Kligfield P, Janse M, Camm J (eds) Comprehensive electrocardiology, vol 4. Springer, London, p 1922

Dwyer CM, Conington J, Corbiere F, Holmøy IH, Muri K, Nowak R, Rooke J, Vipond J, Gautier JM (2015) Invited review: Improving neonatal survival in small ruminants: science into practice. Animal. https://doi.org/10.1017/ S1751731115001974

Fazio F, Arfuso F, Giudice E, Giannetto C, Giuseppe P (2016) Physiological differences between twin and single-born lambs and kids during the first month of life. Arch Anim Breed 59:201-207

Finley JP, Nugent ST, Hellenbrand W (1987) Heart-rate variability in children: spectral analysis of developmental changes between 5 and 24 years. Can J Physiol Pharmacol 65(10):2048-2052

Gall C (1996) Goat breeds of the world. Margraf Publishing, Weikersheim

Giannetto C, Arfuso F, Fazio F, Giudice E, Panzera M, Piccione G (2017) Rhythmic function of body temperature, breathing and heart rates in newborn goats and sheep during the first hours of life. J Vet Behav 18:29-36

Glotzbach SF, Edgar DM, Boeddiker M, Ariagno RL (1994) Biological rhythmicity in normal infants during the first three months of life. Pediatrics 94:482-488

Habibu B, Kawu MU, Makun HJ, Aluwong T, Yaqub LS (2016) Seasonal variationin body mass index cardinal physiological variables and serum thyroid hormones profiles in relation to susceptibility to thermal stress in goat kids. Small Rum Res 145:20-27

Habibu B, Kawu MU, Makum HJ, Aluwong T (2017) Influence of seasonal changes on physiological variables, haematology and serum thyroid hormones profile in male Red Sokoto and Sahel goats. J Appl Anim Res 45:508-516

Habibu B, Yaqub LS, Dzenda T, Kawu MU (2019) Sensitivity, impact and consequences of changes in respiratory rate during thermoregulation in livestock. Ann Anim Sci 19(2):291-304

Habibu B (2015) Effects of sex, age, body mass index and season on serum thyroid hormones and thyroid stimulating hormone in Red Sokoto and Sahel goats (M.Sc. thesis). Ahmadu Bello University, Zaria

Hamzaoui S, Salama AAK, Albanell E, Such X, Caja G (2013) Physiological responses and lactational performances of late-lactation dairy goats under heat stress conditions. J Dairy Sci 96:6355-6365

Hilaire G, Duron B (1999) Maturation of the mammalian respiratory system. Physiol Rev 79:325-360

Hutchon DJR (2015) Ventilation before umbilical cord clamping improves physiological transition at birth or "umbilical cord clamping before ventilation is established destabilizes physiological transition at birth. Front Pediatr 3:29

Hutchon DJR (2016) The normal range of heart rate at birth in a healthy term neonate: a critical review of the evidence. Curr Pediatr Res 20(1 \& 2):7-10

Kasari TR (1994) Physiologic mechanisms of Adaptation in the fetal calf at birth Vet Clin N Am Food Anim Pract 10:127-136

Lu DC (1989) Effects of heat stress on goat production. Small Rum Res 2:151-162

Masero EJ, Siegel PD (1977) Acid base regulation, its physiology and pathology and interpretation of blood gas analysis, 2nd edn. W. B. Saunders, Philadelphia

Massin MM, Naeyns K, Withofs N, Ravet F, Gerard P (2000) Circadian rhythm of heart rate and heart rate variability. Arch Dis Child 66:179-182

Minka NS, Ayo JO (2016) Effects of cold-dry (harmattan) and hot-dry seasons on daily rhythms of rectal and body surface temperatures in sheep and goats in a natural tropical environment. J Circad Rhym 14(1):1-11

Mortola JP (1984) Breathing pattern in newborns. J Appl Physiol Respir Environ Exer Physiol 56(6):1533-1540

Ngere LP, Adu IF, Okubanjo O (1984) The indigenous goats of Nigeria. Anim Gen Res Inform 3:1-9

Piccione G, Grasso F, Giudice E (2005) Circadian rhythm in the cardiovascular system of domestic animals. Res Vet Sci 79:155-160

Piccione G, Borruso M, Fazio F, Giannetto C, Caola G (2007) Physiological parameters in lambs during the first 30 days postpartum. Small Rum Res $72: 57-60$

Plush KJ, Hebart ML, Brien FD, Hynd PI (2016) Variation in physiological profiles may explain breed differences in neonatal lamb thermoregulation. Anim Prod Sci 56:746-756

Ravagnolo O, Misztal I, Hoogenboom G (2000) Genetic component of heat stress in dairy cattle, development of heat index function. J Dairy Sci $83: 2120-2125$

Ravary-Plumioen B (2009) Resuscitation procedures and life support of the newborn calf. Rev Med Vét 160:410-419

Refinetti R (2006) Circadian physiology, 2nd edn. Taylor and Francis, Boca Raton

Saddiqi HA, Nisa M, Mukhtar N, Shahzad MA, Jabbar A, Sarwar M (2011) Documentation of physiological parameters and blood profile in newly born Kajli Lambs. Asian-Australas J Anim Sci 24:912-918

Samimi AS (2019) Changes of clinical, electrolytes, acute phase proteins, and some cardiovascular biomarkers in lambs and kids from birth to 2 days of age. Trop Anim Health Prod. https://doi.org/10.1007/s11250-019-01845-x

Temizel EM, Senturk S, Kasap S (2009) Clinical, haematological and biochemical findings in Saanen goat kids with naturally occurring heat stroke. Tier Prax Grob 37(G):236-241

von Walter LW, Lidfors L, Madej A, Dahlborn K, Hydbring-Sandberg E (2010) Cardiovascular, endocrine and behavioural responses to suckling and permanent separation in goats. Act Vet Scand 52:51

Weinert D, Sitka U, Minors DS, Waterhouse JM (1994) The development of circadian rhythmicity in neonates. Early Hum Dev 36:117-126

Yaqub LS, Ayo JO, Habibu B, Lawal M, Kawu MU, Rekwot PI (2021) Thermoregulatory, oxidative stress and lipid responses in prepartum ewes administered with I-carnosine during the hot-dry season. Trop Anim Health Prod. https://doi.org/10.1007/s11250-021-02832-x

\section{Publisher's Note}

Springer Nature remains neutral with regard to jurisdictional claims in published maps and institutional affiliations. 